KFKI-1980-46

T, I, GOMBOS I

A. J, OWENS

THE INTERPLANETARY TRANSPORT OF SOLAR COSMIC RAYS

Hungarian Academy of Sciences

CENTRAL

RESEARCH

INSTITUTE FOR

PHYSICS

BUDAPEST 


\title{
THE INTERPLANETARY TRANSPORT OF SOLAR COSMIC RAYS
}

\author{
Tamás I. Gombosi
}

Central Research Institute for Physics H-1525 Budapest 114, P.O.B. 49, Hungary

Aaron J. Owens

Bartol Research Foundation of the Franklin Institute University of Delaware

Newark, Delaware 19711, USA

To appear in Astrophysical Journal Letters 


\section{ABSTRACT}

Numerical solutions are presented for the propagation of solar cosmic rays in interplanetary space, including the effects of pitch-angle scattering and adiabatic focusing. The intensity-time profiles can be well fitted by a simple radial spatial diffusion equation with scattering mean-free path $\lambda_{f i t}$. The radial mean-free path so obtained is significantly larger than the true scattering mean-free path for low-rigidity particles due to both adiabatic focusing and the inapplicability of the diffusive approximation early in the event. The well-known discrepancy between $\lambda_{f i t}$ and the theoretical predictions may be resolved by these calculations.

\section{АННОТАЦИЯ}

Численным методом изучается распространение солнечных космических лучей в межпланетном пространстве с учетом влияния адиабатической фокусировки и рассеяния по пич-углам. Полученные временные изменения профилей интенсивностей могут быть хорошо аппроксимированы решением простого уравнения радиальной диффузии, где свободный пробег для рассеяния - $\lambda_{f i}$. Из-за адиабатической фокусировки и большой ошиєки диффузионного приближения в начальной фазе после инжекции в случае частиц с малой жесткостью свободный пробег для радиальной диффузии гораздо болыше, чем действительный свободный пробег. Данный результат позволяет разрешить известное противоречие между наблюдаемыми и теоретически предсказанными значениями $\lambda$.

\section{KIVONAT}

Numerikusan vizsgáljuk a szoláris kozmikus sugárzás bolygóközi terjedését az adiabatikus fókuszálás és mágneses irányszögszórás hatásait figyelembe véve. A kapott intenzitás-idô profilok jôl közelithetôek egy egyszerü radiális diffuziós egyenlet megoldásával, ahol a szóródási szabad uthossz $\lambda_{f i t}$. Kis merevségü részecskék esetén az adiabatikus fókuszálás és a diffuziós közelités a kibocsátás utáni kezdeti szakaszban való nagy hibája miatt a radiális diffuziós szabad uthossz lényegesen nagyobb, mint a valódi szabad uthossz. Ez az eredmény feloldhatja az észlelt és az elméletileg jósolt $\lambda$ értékek közötti jól ismert ellentmondást. 


\section{INTRODUCTION}

Since the pioneering work of Meyer, et al. $\mid 1956 /$, it has been customary to model the interplanetary propagation of solar cosmic rays by a time-dependent spatial diffusion equation of the form

$$
\partial U / \partial t=\left(1 / r^{2}\right) \partial / \partial r\left\{r^{2} K r r U / \partial r\right\}
$$

$|1 a|$

where $U$ is the omnidirectional intensity and $K_{r r}=(1 / 3) \lambda_{r} w$ is the radial diffusion coefficient for particles with speed $w$. The effects of convection and adiabatic deceleration by the radially expanding solar wind must also be considered /e.g., Jokipii, 1971; Scholer, 1976/. These latter effects are relatively unimportant until late in the event $\left(t>>t_{\max }\right)$ if $\lambda_{r} \gtrsim 0.1$ a.u., as is observed /Zwick1 and Webber, 1977a, 1977b; Owens, 1979/.

If the radial diffusion coefficient is independent of the distance from the sun, and the particles diffuse into infinite space, the solution to equation $\mid l a /$ is simply

$$
U(r, t)=A t^{-3 / 2} \exp \left(-r^{2} / 4 K_{r r} t\right)
$$

$|1 \mathrm{~b}|$

where $\mathrm{A}$ is a constant. Recent spacecraft have gone beyond $20 \mathrm{a} \cdot \mathrm{u}$. without finding a free-escape boundary for cosmic rays.

More fundamental than the spatial diffusion equation is the pitch-angle scattering eqaution in phase space /Jokipi1, 1966, 1971; Roelof, 1966, 1969; Earl, 1974, 1976; Luhmann, 1976/,

$$
\partial F / \partial t+w \mu \partial F / \partial z+(w / 2 L) \partial / \partial \mu\left\{\left(1-\mu^{2}\right) F\right\}=\partial / \partial \mu\left(D_{\mu \mu} \partial F / \partial \mu\right)
$$

Here $F$ represents the number of energetic particles per unit length along a magnetic field line, or the phase-space density $n$ multiplied by the cross-sectional area of a flux tube. The magnetic field points in the $z$ direction and has a magnitude scale length $L=-(1 / B) d B / d z$. The particle's pitch-angle cosine $\mu=w_{z} / w$ and $D_{\mu \mu}$ is the pitch-angle scattering coefficient. Under a set of assumptions including slow temporal evolution and small anisotropy, equation $|2|$ reduces to equation $\mid l a /$, where the spatial diffusion co- 
efficient 1s /Jokip11, 1971; Ear1, 1974; Luhmann, 1976/

$$
K_{r r}=K_{I I} \text { os }{ }^{2} \psi=\cos ^{2} \psi\left(w^{2} / 4\right) \int_{0}^{1}\left(1-\mu^{2}\right)^{2} / D_{\mu \mu} d \mu
$$

Here $\psi$ is the Parker spiral angle between the interplanetary magnetic field /IMF/ and heliocentric radius vectors. The corresponding mean-free path is

$$
\lambda_{r}=3 \mathrm{~K}_{r r} / \mathrm{w}
$$

Experimental intensity-time profiles are often fit to equations $\mid 1 /$, perhaps including convection and deceleration, to determine the "observed" mean-free path $\lambda_{\mathrm{fit}}=3 \mathrm{~K}_{\mathrm{rr}}^{\mathrm{fit}} / \mathrm{w}$. Zwick1 and Webber $/ 1977 \mathrm{a} /$ analyzed a large set of spacecraft measurements with this method and found that the observed $\lambda_{\text {fit }}$ for $\sim 10$ $\mathrm{MeV}$ protons is about a factor of 10 larger than the value derived from quasilinear theory /QLT/ and equations /3/ - /4/ /Jokipii, 1966, 1971; Roelof, 1966; Hasselmann and Wibberenz, 1968/.

The discrepancy $\lambda_{f i t}>\lambda_{r}$ has been known for some time, and along with some theoretical arguments it lead to suggestions that the quasi-linear results for $\mathrm{D}_{\mu \mu}$ are incorrect /e.g., Klimas and Sandri, 1971/. Subsequent theoretical /Völk, 1973; Goldstein, 1976/ and Monte Carlo /Jones, et al., 1973; Kaiser, et al., 1978; Owens and Gombosi, 1980/ work has shown that the non-linear corrections to the QLT results for $D_{\mu \mu}$ are surprisingly small. If anything, in the "slab model" with magnetic-field fluctuations propagating along the average field, QLT somewhat underestimates the scattering, so non-linear effects are unlikely to resolve the $\lambda_{f i t}>\lambda_{r}$ discrepancy.

Recently, Goldstein $/ 1980 /$ has proposed that the problem is an improper characterization of the magnetic-field fluctuations, since they appear to be more in the nature of a rotating fixed-length vector / Lichtenstein and Sonett; $1980 /$ rather than two independently-varying transverse components /as in the slab model/.

We show here that another resolution of the $\lambda_{f i t}>\lambda_{r}$ discrepancy is possible, even within the context of the slab model and QLT. Since the anisotropy of solar flare events is large, equation $/ 2 /$ rather than equation /la/ should be used. The diffusive idealization upon which equation $/ \mathrm{la} /$ is based is inapplicable during the initial phases of solar particle events, because both the time evolution of the particle distribution and the anisotropy are large.

of course, it has long been known that the diffusive idealization is inapplicable for a rapidly-evolving particle distribution /e.g., Jokipit, 1971; Earl, 1974/. The importance of adiabatic focusing and non-diffusive transport was emphasized in important work by Earl /1976/ and Bieber /1977/. In these models, the length scale $L$ of the interplanetary magnetic field's size is taken to be constant, so the IMF diverges exponentially with distance from the sun. This model, including effects of coronal transport, has been shown to fit a large number of solar-flare profiles/Ma Sung and Earl, 1978/. Recent 
work by Bieber et al. /1979/ indicates that the model can also fit the detailed anisotropy profile of some events. However, the numerical calculations of $\mathrm{Ng}$ and Wong /1979/ show that the use of a constant focusing length L significantly overestimates the influence of adiabatic focusing compared with the more realistic Parker spiral interplanetary magnetic field geometry. The exponentially diverging field model gives a more rapid decay of the particle intensity after the time of maximum than occurs in the spiral IMF. Since our numerical calculations confirm the results of $\mathrm{Ng}$ and Wong, we suggest that the conclusion of Earl and co-workers that the observed $\lambda_{f i t}$ is much larger than the value obtained from quasi-linear theory may have to be re-examined.

We have used $\mathrm{Ng}$ and Wong's numerical technique to investigate the propagation of solar cosmic rays over a wide range of rigidities. We find that low-energy particles arrive at earth much more rapidly than equation / $/ \mathrm{b} /$ predicts. Thus fits to intensity-time profiles using a spatial diffusion equation /like our equation la/ significantly overestimate the scattering mean-free path. Out calculations show that $\lambda_{\text {fit }} \sim 0.1$ a.u. for a wide range of particle rigidities $10.01 \mathrm{GV} \lesssim \mathrm{R} \lesssim 0.5 \mathrm{GV} /$ even though the actual $\lambda_{r}$ can be more than a factor of 10 smaller.

\section{NUMERICAL SOLUTIONS OF THE TRANSPORT EQUATION}

Following $\mathrm{Ng}$ and Wong /1979/, we solve equation $/ 2 /$ by a numerical finite-difference technique. We define the dimensionless time $\tau=w t / \ell$ and position in space $n=\ln (r / \ell)$, where we choose the scaling length $\ell$ to be the correlation length of the IMF fluctuations,

$$
\ell=10^{12} \mathrm{~cm}
$$

/Hedgecock, 1975/. The magnetic field in the solar equatorial plane is taken to be an Archimedes spiral, with focusing length $L=-(1 / B) d B / d z$ varying with radial position accordingly. We use the slab model and QLT to calculate the pitch-angle scattering coefficient,

$$
D_{\mu \mu}=(w / \ell) D_{0}\left(1-\mu^{2}\right) \sqrt{\mu}
$$

where

$$
D_{0}=0.65\left(\mathrm{r}_{\mathrm{g}} / \ell\right)^{-1 / 2}<\delta \mathrm{B}_{\mathrm{x}}^{2}>/ \mathrm{B}_{\mathrm{O}}^{2}
$$

Here $r_{g}$ is the particle's gyroradius in the $5 \gamma$ IMF /near earth/, and $\angle \delta \mathrm{B}_{\mathrm{x}}{ }^{2}>/ \mathrm{B}_{\mathrm{O}}{ }^{2}=1 / 4$ is the relative variance of a component of the IMF perpendicular to the average field /Hedgecock, 1975/.

Equation $/ 2 /$, in these dimensionless units, becomes 


$$
\begin{aligned}
\partial F / \partial \tau & =D_{0} \partial / \partial \mu\left\{\left(1-\mu^{2}\right) \sqrt{\mu} \partial F / \partial \mu\right\}-\mu g(n) \partial F / \partial n \\
& -(\ell / 2 L) \partial / \partial \mu\left\{\left(1-\mu^{2}\right) F\right\}
\end{aligned}
$$

Here $g(n)$ gives the transformation from the field aligned $\mathrm{z}$ to $n=\ln (\mathrm{r} / \mathrm{l})$. For a fixed IMF power spectrum, the single parameter in the models is the dimensionless size of the pitch-angle scattering coefficient, $D_{O}$, which we take to be a constant throughout the solar system. $D_{0}$ constant requires the fluctuations to scale as $\left(\delta_{\mathrm{B}_{\mathrm{x}}}\right) \mathrm{rms} \propto \mathrm{B}_{\mathrm{O}}{ }^{3 / 4}$. The parallel diffusion coefficient and mean-free path, calculated from equation $/ 3 /$, are thus independent of heliocentric radius and we have simply

$$
\lambda_{r}=1.2 \cos ^{2} \psi l / D_{0}=(0.04 \mathrm{a} \cdot \mathrm{u} \cdot) / \mathrm{D}_{0}
$$

The particle rigidity $\mathrm{R}$ and $\mathrm{D}_{0}$ are simply related by

$$
D_{0}=0.6\{(1 \mathrm{GV}) / R\}^{1 / 2}
$$

In our numerical code, particles are injected near the sun $1 / r=0.1 \mathrm{a} . \mathrm{u} .1$ with velocities spread smoothly over positive values of $\mu$. We imposed a free-escape condition $/ F=0 /$ at an outer radial distance $r=R_{0}$. The anisotropies and temporal profiles inside $1 \mathrm{a} \cdot \mathrm{u}$. were unaffected by the choice of $R_{0}$ in the range investigated /5 a.u. $\leq R_{0} \leq 15 \mathrm{a} \cdot \mathrm{u} . /$. As done by $\mathrm{Ng}$ and Wong /1979/, for numerical stability we integrated with respect to $n$ in opposite directions for $\mu<0$, and we matched the fluxes through $\mu=0$ to join the two halves of the solution.

We checked our numerical integration code for some simple cases and via a detailed comparison with $\mathrm{Ng}$ and Wong's published profiles. A typical intensity-time profile and representative anisotropy diagrams are shown in Figure 1 , which is relevant for $\sim 1 \mathrm{MeV}$ protons. The time scale is such that $\tau=120$ is 1 day. The calculated intensity-time profile /solid curve/ is well approximated by a simple diffusion profile /equation $1 \mathrm{~b} /$ with mean-free path $\lambda_{f i t}=$ $=0.09 \mathrm{a} . \mathrm{u}$. The actual scattering mean-free path, calculated from equation /7/ via QLT, is $\lambda_{r}=0.01 \mathrm{a} . \mathrm{u}$. The dashed curve shows that using a spatial diffusion profile /equation $1 \mathrm{~b} /$ with the actual value of $\lambda_{r}$ gives a much more slowly-evolving profile than the numerical solution to equation $/ 2 /$. The anisotropy diagrams show the "mushroom" shape discussed by Bieber /1977 for this power spectrum.

Although equation $\mid 1 \mathrm{~b} /$ can accurately fit the temporal profile, Figure 2 shows that the corresponding anisotropies are not the same, although they are similar in magnitude. An additional point shown in Figure 2 is that in our numerical solutions to equation $/ 2 /$ the anisotropy as a function of time is strongly dependent upon the amount of scattering, while simple diffusion lequation $1 \mathrm{~b} /$ gives an anisotropy $3 r /(2 \mathrm{wt})$ that is independent of $\mathrm{K}_{\mathrm{rr}}$. Thus the use of anisotropy as well as temporal profile data is extremely important 


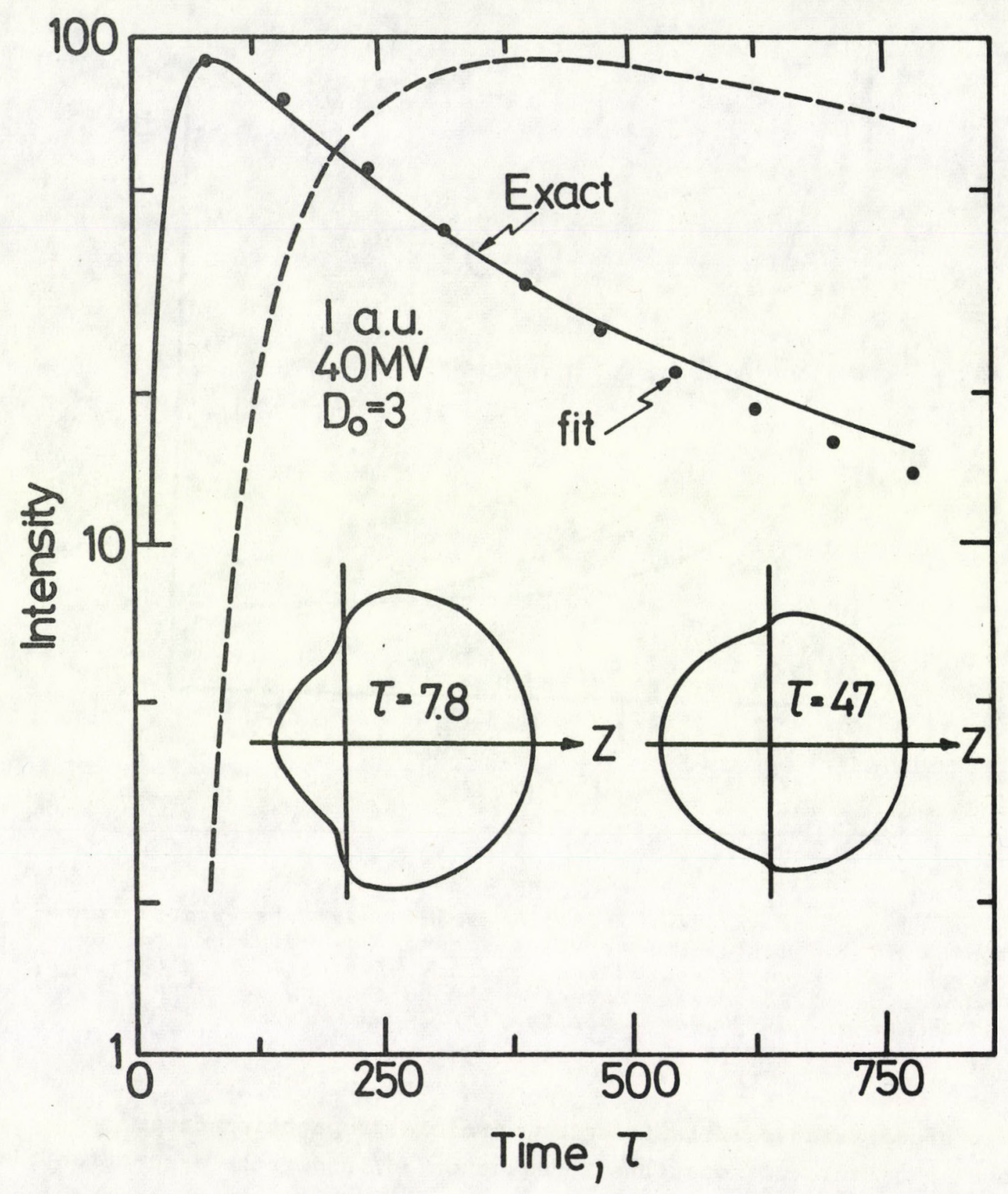

Figure 1.

Intensity-time profiles for solar cosmic rays observed at earth. The solid curve is the numerical solution to the focused pitch- angle scattering equation, for the parameter $D_{0}=3$. The dashed curve is the spherically-symmetric spatial diffusion profile obtained using the actual mean-free path $/ \lambda_{p}=0.013 \mathrm{a} \cdot \mathrm{u} . \mathrm{l}$, and the dots show a fitted spatial diffusion profile with $\lambda_{f i t}=0.09 a . u$. The lower two diagrams show the pitch-angle distribution for two selected times. 


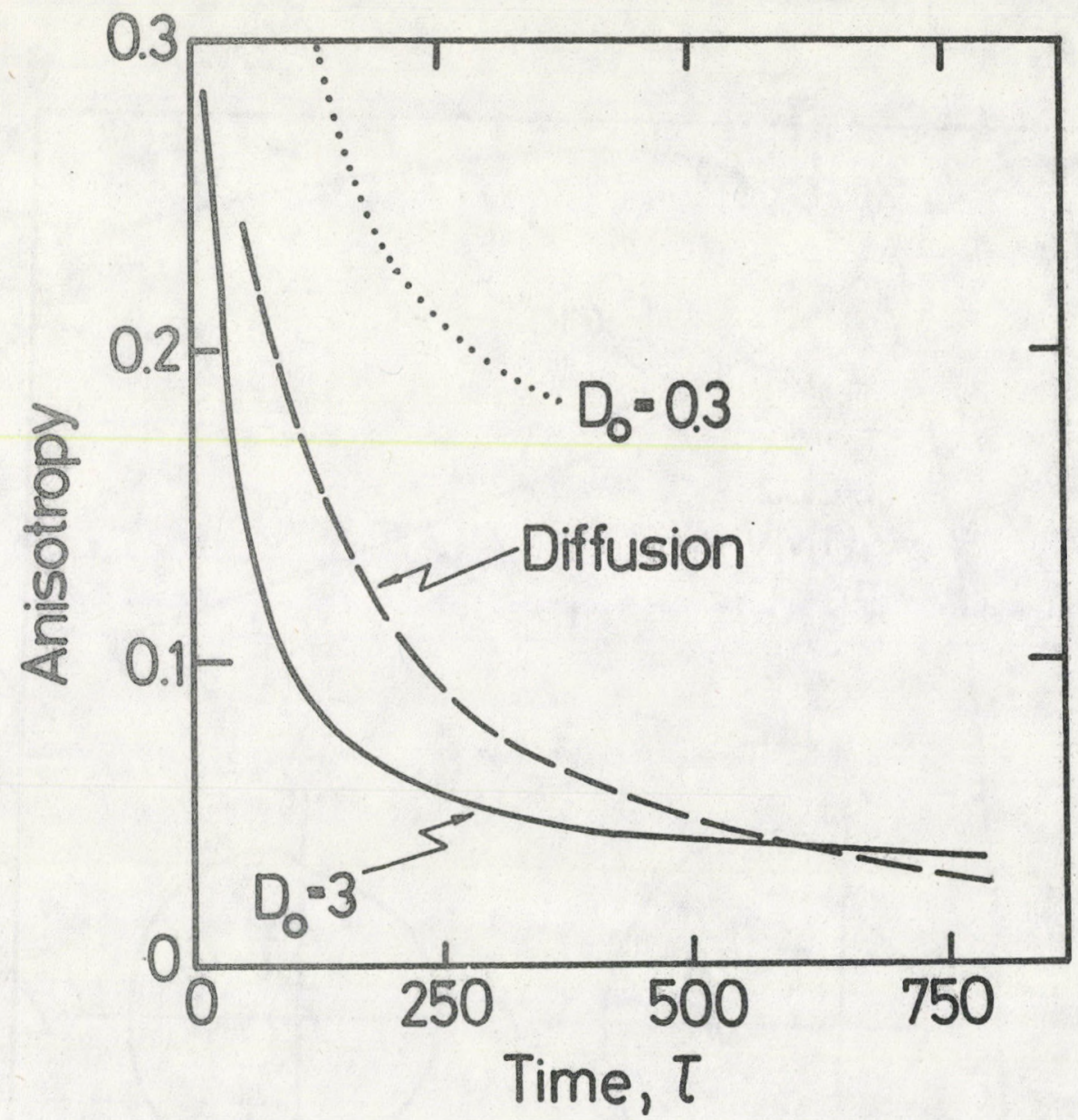

Figure 2.

Anisotropy-time profiles for solar cosmic rays observed at earth. The solid and dotted curves are the numerical solutions to the focused pitch-angle scattering equation, for $D_{0}=3$ and $D_{0}=0.3$, respectively. The dashed curve is the anisotropy corresponding to the simple diffusion equation $/ 1 \mathrm{~b} /$.

in the interpretation of fits to solar particle propagation data.

We also calculated solutions to equation $/ 6 /$ under the assumption that the relative magnetic-field fluctuations $\left(\mathrm{SB}_{\mathrm{x}}\right)_{\mathrm{rms}} / \mathrm{B}_{0}$ are constant throughout the solar system. This variation gives more scattering near the sun than in the constant $D_{0}$ models. The solutions are very similar to those discussed here. At earth, for example, the parameter $\lambda_{f i t}$ varies by less than $5 \%$ from the constant $D_{0}$ to the constant $\left(\delta_{\mathrm{x}}\right) \mathrm{rms}_{\mathrm{B}} / \mathrm{B}_{\mathrm{O}}$ model.

We interpret the results shown in Figure 1 like this. During the early phases of the solar flare event, particles propagate through space much more rapidly than equations / / / predict, because in the initial large-anisotropy phase a telegrapher's type equation is more appropriate then the diffusive one. We verified that adiabatic focusing has little affect on the intensity profile shown in Figure 1 by taking the focusing length arbitrarily large. 
In the onset phase of the solar particle event, the first particles that reach earth are those few that traverse the interplanetary medium essentially without scattering. Since for $\mu \sim 1$ the pitch-angle scattering coefficient $D_{\mu \mu} \propto\left(1-\mu^{2}\right)$, there is little scattering of field-aligned particles and their transit is essentially rectilinear. The initial arrival of particles then depends only on their speed and is independent of $D_{\mu \mu}$. Late in the event, the temporal profile depends only on the geometrical properties of the field and is Independent of $D_{\mu \mu}$ as long as scattering is strong enough. In equation $\mid \mathrm{lb} /$, for example, at late times the profile is dominated by the $t^{-3 / 2}$ "geometrical" factor and is independent of $\mathrm{K}_{\mathrm{rr}}$. Thus, for a sufficiently large amount of scattering, the temporal profile is dominated by simple rectilinear transport for early times and the geometry of the field for late times, and the amount of scattering is relatively unimportant. This explains the flattening of $\lambda_{\text {fit }}$ curve in Figure 3 for $\mathrm{R}<1$ GV. In our dimensionless units, the intensity-time profiles for $R<1$ GV are quite similar in shape.

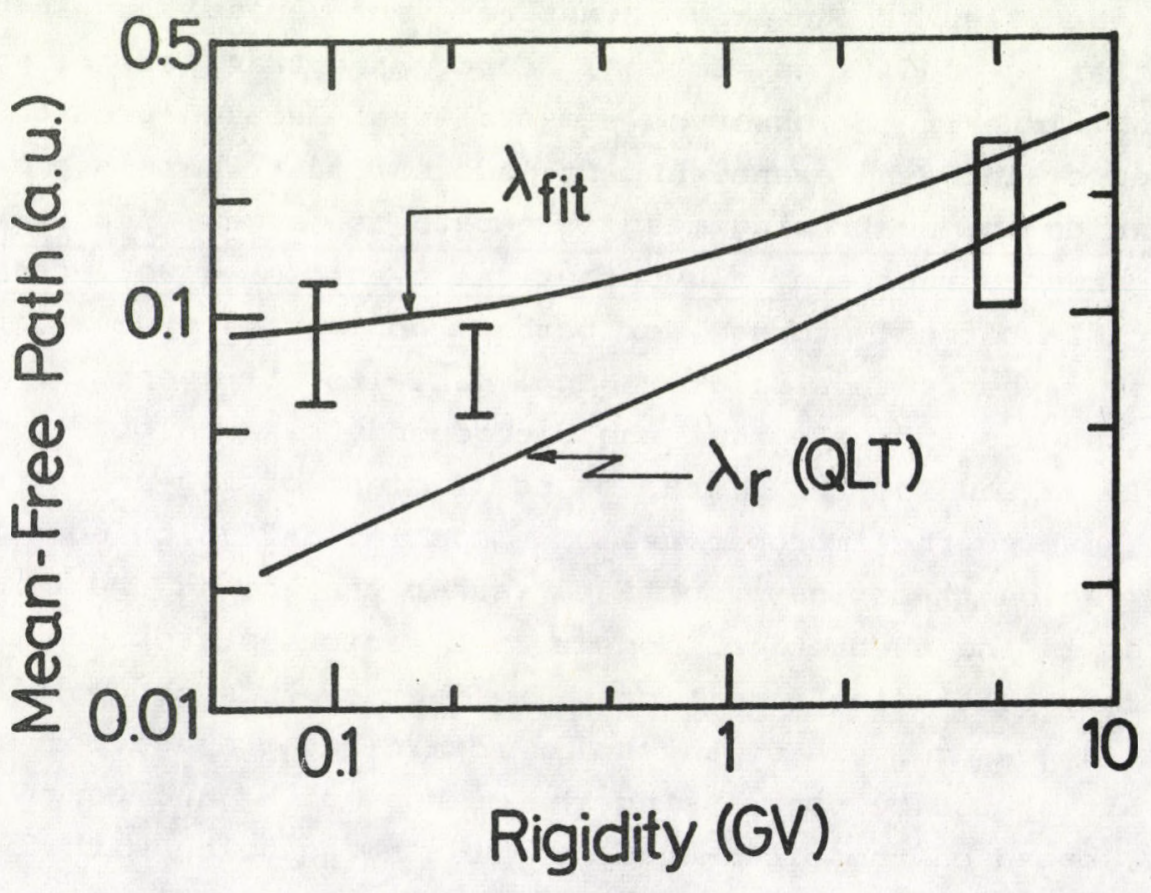

Figure 3.

The solid line gives the actual mean-free path used in the calculations, based on QLT. The other curve represents the mean-free path obtained by fitting the actual calculated profiles to a spherically-symmetry spatial diffusion model /equation $1 \mathrm{~b} /$. The points are the experimental values of $Z$ wickl and Webber $/ 1977 \mathrm{a} /$, and the box is our rough estimate based on a few neutron-monitor events. Zwickl and Webber /1977b/ show that $\lambda_{f i t}$ is essentially constant for $1 \mathrm{MV} \lesssim R \lesssim 100 \mathrm{MV}$. 


\section{DISCUSSION}

Figure 3 gives the primary result of this investigation. It shows that the radial mean-free path deduced from observed profiles will be significant$I_{Y}$ over-estimated, if a spatial diffusion model as in equations $/ 1 /$ is used to fit temporal profiles of solar cosmic rays. The solutions to the pitch-angle scattering equation, including focusing, give a much more rapid profile than equaiton $/ \mathrm{lb} /$ indicates for low rigidities / see Figure $1 /$. Some observational points are shown in Figure 3 /Zwickl and Webber, 1977a/, and they show the same features as our $\lambda_{f i t}$ curve. Using a collection of other spacecraft data, Zwickl and Webber $/ 1977 \mathrm{~b} /$ show that the $\lambda_{\text {fit }}$ curve is rigidity-independent down to $1 \mathrm{MV}$, in agreement with our calculations. The actual scattering mean-free path, determined from the equation $/ 3 /$ with the $D_{\mu \mu}$ used in the solutions, is considerably smaller than $\lambda_{\text {fit }}$ for $R<<1 \mathrm{GV}$.

Thus we conclude that the simple diffusion picture for solar-particle transport can give quite misleading results. Although the intensity-time profiles "look" diffusive, for small scattering mean-free paths $/ \lambda_{r} \lesssim 0.1$ a.u./ the fitted profiles significantly over-estimate $\lambda_{r}$. For simplicity in our discussion here, we have not mentioned the influences of prolonged coronal injection of particles or the large event-to-event variability in the interplanetary scattering conditions. Coronal storage and transport of particles will increase the width of the observed temporal profiles and produce a large anisotropy longer into the event. And it is clear that there are occasionally events in which the scattering mean-free path is large $/ \sim 1$ a.u.l Our Figure 3 should be taken to represent a hypothetical event for a well-connected flare with negligible coronal storage, or perhaps an average over a large number of such flares, rather than a relation applicable to all events.

These results indicate that the discrepency between observed and theoretical /QLT/ values for the diffusion coefficient of low-energy solar cosmic rays may be due to the improper use of a spatial diffusion equation in circumstances for which it is inappropriate, rather than being due to some fundamental error in the theoretical models or a serious misrepresentation of the interplanetary scattering conditions. In light of this conclusion, it is suggested that a new analysis of the solar cosmic-ray propagation data obtained on spacecraft should be done, using the methods of $\mathrm{Ng}$ and Wong /1979/ and this paper, based on the pitch-angle scattering equation with focusing, rather then on a spatial diffusion equation. For a first approximation, our Figure 3 gives the relationship between the reported $\lambda_{\text {fit }}$ determined using diffusion models and the actual mean-free path $\lambda_{r}$.

Our calculations neglect the contributions of adiabatic deceleration and convection. As discussed above, these effects are important for cases in which $\lambda_{\text {fit }}$ is smaller than about $0.1 \mathrm{a} . \mathrm{u}$. The inclusion of convection and adiabatic deceleration into our equation $/ 2 /$ is understood theoretically /Luhmann, 1976/: additional momentum-dependent terms are introduced on the right-hand side of the equation. The momentum loss is then pitch-angle dependent, and the calcu- 
lations must be carried out in a three-dimensional array /position, $\mu$, and momentum/ rather than the two-dimensional calculation /position, $\mu /$ that we have done. Although the computing time is considerable, in light of the results discussed here we believe that this is the only accurate way to determine the diffusive scattering mean-free path for solar particles with rigidities less than about 1 GV. Adiabatic focusing and a large initial anisotropy together invalidate the assumptions underlying the derivation of the spatial diffusion equation for low-rigidity solar-flare particles.

\section{ACKNOWLEDGEMENTS}

We thank J.R. Jokipii, C.K. Ng, and I.D. Palmer for several helpful discussions. This work was done while T.I.G. was a Visiting Scientist at the University of Michigan, where Prof. A.F. Nagy's hospitality is gratefully acknowledged. This research was supported, in part, by the National Science Foundation through grants DPP 76-23429 and ATM 77-12615/A.J.O./ and by NASA through grants NGR23-005-O15 and NASA ARC Contract No. NAS2-9130 at the University of Michigan /T.I.G./.

\section{REFERENCES}

Bieber, J.w., 1977, Ph. D. Thesis, University of Maryland, College Park; Bieber, J.W., Earl, J.A., Green, G., Kunow, H., Müller-Mellin, R., and Wibberenz, G., 1979, 16th Int. Cosmic Ray Conf., Kyoto, 5, 246;

Earl, J.A., 1974, Ap. J., 193, 231;

Earl, J.A., 1976, Ap. J., 205, 900;

Goldstein, M.L., 1976, Ap. J., 204, 900;

Goldstein, M.L., 1980, J. Geophys. Res., in press;

Hasselmann, K., and Wibberenz, G., 1968, z. Geophys., 34, 353;

Hedgecock, P.C., 1975, Solar Phys., 42, 497;

Jokipii, J.R., 1966, Ap. J., 146, 480;

Jokipii, J.R., 1971, Rev. Geophys. Space Phys., 9, 27;

Jones. F.C., Birmingham, T.J., Kaiser, T.B., 1978, Phys. Fluids, 21, 347;

31,485

Jones, F.C., Kaiser, T.B., and Birmingham, T.J., 1973, Phys. Rev. Lett.,

Kaiser, T.B., Birmingham, T.J., and Jones, F.C., 1978, Phys. Fluids, 21,

Klimas, A., and Sandri, G., 1971, Ap. J., 1969, 41;

Lichtenstein, B.R., and Sonett, S.P., 1980, Geophys. Res. Lett., 7, 189;

Luhmann, J.G., 1976, J. Geophys. Res., 81, 2089;

Ma Sung, L.S., and Earl, J.A., 1978, Ap. J., 222, 1080;

Meyer, P., Parker, E.N., and Simpson, J.A., 1956, Phys. Rev., 101, 1397;

252;

Ng. C.K., and Wong, K.-Y., 1979, 16 th Int. Cosmic Ray Conf., Kyoto, 5,

Owens, A.J., 1979, J. Geophys. Res., 84, 4451;

Owens, A.J., and Gombosi, T., 1980, Ap. J., 235, 1071;

Roelof, E.C., 1966, Ph. D. Thesis, University of California, Berkeley;

Roelof, E.C., 1969, in H. Ogelman and J.R. Wayland, ed., Lectures in

High Energy Astrophysics, Washington, NASA SP-199;

Völk, H.J., 1973, Ap. Space Sci., 25, 471;

Zwickl, R.D., and Webber, W.R., 1977a, Solar Phys., 54, 457;

Zwick 1, R.D., and Webber, W.R., 1977b, 15th Int. Cosmic Ray Conf.,

Plovdiv, 5, 160; 



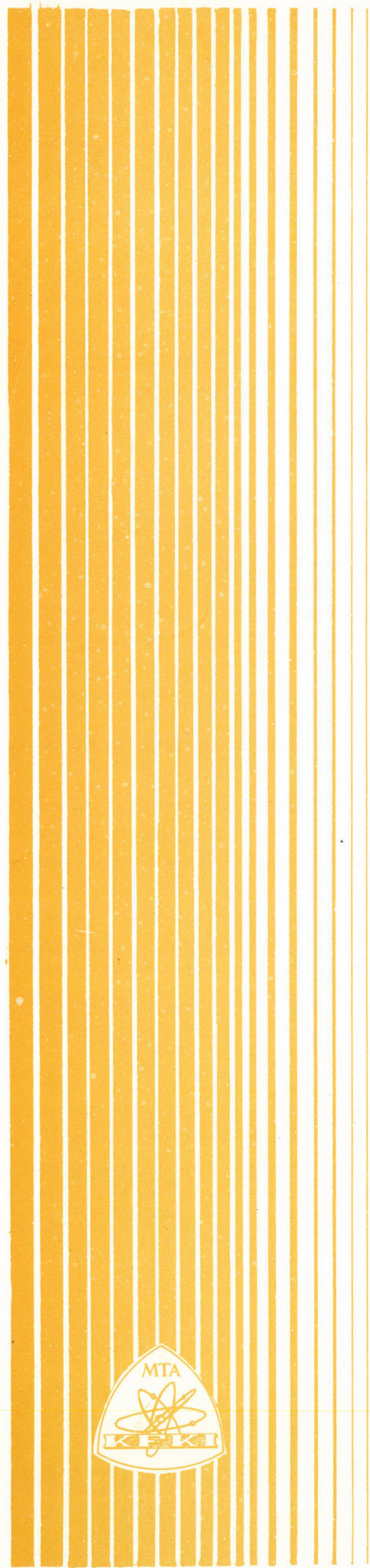

Kiadja a Központi Fizikai Kutató Intézet Felelõs kiadó: Szegõ Károly Szakmai lektor: Kóta József Nyelvi lektor: Benkó György Példányszám: 390 Törzsszám: 80-439 Készült a KFKI sokszorositó üzemében Budapest, 1980. julius hó 